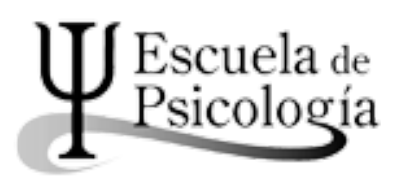

Wímblu, Rev. estudiantes Esc. de psicología, Univ. de Costa Rica. 12 (2): 29-42, 2017 / ISSN: 1659-2107

\title{
El cine corporizado como propuesta política1
}

\author{
Cinema embodied as a political proposal
}

Mariana Alpizar Guerrero*

\begin{abstract}
Resumen: En este artículo se propone la categoría de cine corporizado para nombrar propuestas artísticas que se dan en el audiovisual desde una posición de crítica radical, como es el caso del cine de autor y específicamente de películas de Jean Luc-Godard, fundamentalmente las presentadas en los años 60s. Estos filmes cuestionan las dicotomías cuerpo-mente, razón-emoción y ética-estética cuando conjugan estos aspectos para entablar un diálogo con los sujetos que miran, dándoles así un lugar de agenciamiento político e invitándoles a realizar transformaciones colectivas pero también personales. De acuerdo a la anterior propuesta se realiza un recorrido a través de cuatro apartados en donde se intentan analizar forma, fondo, subjetivación, ideología, ética y estética, con ejemplos concretos de la obra godardiana. El primero de ellos se denomina La técnica y estética en el cine posmoderno, el segundo Expresión de subjetividad como forma de activismo y el tercero ¿Materialidad versus subjetividad? Una dicotomía que se cuestiona en el cine corporizado, por último Ética y estética como forma de rebelión. A partir de ello se busca no sólo hacer una descripción del concepto propuesto sino, fundamentalmente, iniciar un diálogo entre quienes leen y quien escribe, también como forma de ruptura de las barreras entre palabra y acción.
\end{abstract}

Palabras clave: cine corporizado, ética, estética, subjetividad, Godard.

1 Este artículo fue realizado en el marco del Seminario de Judith Butler, impartido por Camilo Retana, a quien se le agradece su apertura para la escritura del presente texto que busca una interdisciplinariedad con el uso de diversas herramientas de varias disciplinas tanto de las Artes y Letras como de las Ciencias Sociales. Además fue presentado como ponencia en el Coloquio Psinema de la Escuela de Psicología de la Universidad de Costa Rica, organizado por el Núcleo de Cursos Intermedios.

* Universidad de Costa Rica. Bachiller en Psicología. Costa Rica.

Correo electrónico: mariana.Ipzr@gmail.com

Recepción: 28/3/2017 Aceptación: 20/8/2017 
Abstract: In this article the category of embodied film intends to name artistic proposals given in the new wave from a position of radical criticism, such as arthouse and specifically films of Jean Luc-Godard, mainly those presented in the 60s. These films question the dichotomy body-mind, emotion-reason and ethical-aesthetic when these aspects combine to create a dialogue with subjects that look, giving them a place of political agenciamiento and inviting them to make collective but personal transformations. According to previous proposal a tour of three sections where the shape background, subjectivity, ideology, ethics and aesthetics, with concrete examples of backgrd work is performed analyzes. The first one is called The technical and aesthes of Godard work is performed analyzes. The first one is called The technical and aesthetic in postmodern cinema, the second expression of subjectivity as a form of activism and Materiality versus subjectivity? A dichotomy that questions the film embodied. Finally Ethics and aesthetics as a form of rebellion. From this it seeks not only to provide a description of the proposed concept but essentially initiate a dialogue between those who read and who writes, also as a way of breaking the barriers between word and deed.

Key Words: embodied cinema, ethics, aesthetics, subjectivity, Godard.

\section{Introducción}

La Modernidad representa, en la cultura occidental, la separación radical en fragmentos de nuestra vida cotidiana y de nuestra existencia, así como la reducción del cuerpo a lo físico y del alma a lo espiritual-sensitivo. En ese escenario, el cuerpo es considerado como algo dado, biológico des-historizado e incuestionable, es decir, es sólo una "realidad material", un ente separado del alma. Debido a que en las sociedades capitalistas y patriarcales, lo material es considerado primordial, mientras que las emociones, sensaciones y lo que no se puede ver, tiene el lugar de la marginalidad, la división binaria entre alma y cuerpo termina convirtiéndose en una justificación de las jerarquías existentes.

Ante este panorama, tal como lo plantea Foucault de manera transversal en sus obras, se intenta construir institucionalmente un sujeto binario, que piense y sienta por separado, que haga y teorice en momentos distintos, que sea hombre o sea mujer de manera excluyente (entendiendo que lo femenino se relaciona con la pasividad y la emotividad, mientras que lo masculino se relaciona con la actividad y la racionalidad). Estas divisiones intentan disciplinar nuestros cuerpos, de manera tal que sólo sintamos dentro de las leyes establecidas y no pensemos más allá de los límites. Sin embargo, toda ley tiene grietas y la heteronorma patriarcalcapitalista que nos manda a fragmentar nuestras vidas en pequeños pedazos políticamente correctos y estereotipados o moralizados a través de la culpa por lo "anormal", es sumamente frágil, sobre todo cuando observamos que en la vida cotidiana no sólo se rompen los esquemas planteados por el binarismo sino que queda en evidencia la performatividad de esa norma, debido a que esta sólo existe a través de la repetición constante de conductas instauradas culturalmente y no de una supuesta naturaleza que hace posible esa norma (Butler, 1990). E hecho de que ahora sea posible en la academia y en los movimientos sociales con perspectiva feminista-posmoderna, pensar en la ley como hecho histórico construido y no como algo natural que mana de dioses o reyes, ha causado, sin duda alguna, una auténtica revolución epistemológica, dándonos la posibilidad de teorizar de una forma situada, pues, así como la norma es histórica, también nuestro cuerpo lo es (Negri, 2009), tiene tatuados una serie de mandatos y también rupturas de esos mandatos, es decir, posibilidades de agencia.

Justamente, es la "llegada" de la posmodernidad la que, por una parte cuestiona esa binarización de los cuerpos y por otra lleva a las dicotomías a extremo (ambos casos presentes, de manera contradictoria en sociedades actuales). Un ejemplo donde se conjuga el extremo de la dicotomía como una burla a la norma es el de las mujeres trans que asumen la estética femenina hegemónica, pero que desean conservar sus genitales, dejando claro que las mujeres con pene también existen. Es decir, en esa estética también se puede ver una forma de existencia que cuestiona los cánones patriarcales-capitalistas, llevando al extremo algunas leyes del género y rompiendo otras. Es Judith Butler (1990) quien plantea de manera enfática que no existe un continuum total entre sexo-género-deseo, asegurando que los sujetos cambiamos nuestras formas de pensar nuestro sexo, nuestro género y nuestro deseo a lo largo de la vida. Por lo tanto somos cuerpos abiertos, cambiantes, contradictorios y principalmente políticos, es decir, ni siquiera nuestro sexo, algo que considerábamos esencial (de esencia), es puramente biológico. Tal como lo planteó Freud (1905b), la entrada en la cultura se da cuando por ejemplo los niños y las niñas empiezan a utilizar su dedo como forma de sustituir el seno perdido de la madre, entonces el dedo deja de ser sólo una parte del cuerpo y pasa a convertirse en objeto de placer, en metáfora de lo perdido.

Justamente la posmodernidad, como espacio y tiempo actual, abre la posibilidad de reconocer como existentes estéticas no hegemónicas dejando claro que el solo hecho de existir, de vivir con esas corporalidades, puede ser un acto político en momentos donde el autoritarismo institucional es cada vez más fuerte y los sujetos subalternos son censurados (Spivak, 2003), como mínimo, o incluso asesinados en muchos países del mundo (Butler, 2010). Una forma de analizar cómo esas estéticas también pueden convertirse en éticas, siguiendo la línea planteada por Foucault en su libro La hermenéutica del sujeto (1987), es a través de propuestas artísticas posmodernas que conjugan elementos supuestamente dicotómicos y retratan que en la vida real esas dicotomías son más bien absurdas. Todo esto como posición política situada y corporizada.

A partir de esa nueva visión en el arte politizado, se da inicio al cuestionamiento de la norma, empezando por la escritura, fundamentalmente desde la filosofía y la psicología de corte posestructuralista. Sin embargo, en e 
ejercicio de la escritura existe un gran privilegio y es que son los sujetos de saber, sobre todo masculinizados, los que tienen el poder de la palabra. Por su parte en el cine se conjuga el lenguaje escrito, con el visual, lo que no se puede decir y lo que pasa por el cuerpo sin ser apalabrado. A través del audiovisual es posible traspasar lo límites de la razón, pues la temporalidad misma cambia (la imagen no muere a diferencia de la realidad, donde el cuerpo tiene fin), las posibilidades de acción de los sujetos se expanden (en el cine se presentan personas que vuelan y que, por ejemplo, leen el pensamiento), y el cuerpo es ubicado en el lugar de la duda, es flexible, es un producto de la imaginación y a la sigue siendo legible, existe en tanto nos moviliza emocionalmente. Cuando Deleuze habla del cine situado como propuesta política indica: No es que el cuerpo piense, sino que, obstinado, terco, él fuerza a pensar, y fuerza a pensar lo que escapa al pensamiento, la vida. (...) Es por el cuerpo (y ya no por intermedio del cuerpo) como el cine contrae sus nupcias con el espiritu, con el pensamiento. «Dadnos, pues, un cuerpo» es, primeramente, montar la cámara sobre
un cuerpo cotidiano (Deleuze, 1987, p. 251).

Es decir, cuando en el cine-arte posmoderno vemos, por ejemplo, un cuerpo en silencio, como en el caso de la película Persona de Bergman, no estamos con la mente en blanco esperando a que ese sujeto hable, sino que nos reflejamos en su falta de palabra, y se retuercen nuestros propios vacíos, nuestros miedos, nuestra angustia por la falta de certezas y es allí donde da inicio el cuestionamiento, en la propia movilización corporal y en las preguntas: ¿Por qué nos molesta ese silencio? ¿Qué hay detrás de esas emociones? ¿Qué de ese silencio se refleja en nosotras mismas?

Específicamente podemos decir que el cine de autor, posiciona al ser humano como imperfecto, vulnerable y subjetivo y esto es sumamente político. Estudiar, en el cine-cuerpo, la técnica como componente estético y lo ideológico como hecho ético-político lleva a pensar en el arte cinematográfico como una posibilidad revolucionaria, una tecnología social (De Lauretis, 1992) susceptible de ser movilizada y descategorizada. El audiovisual crea aquello que nombra, pero también a través de la imagen puede reconocer sujetos y colectivos sociales que anteriormente no eran reconocidos, puede tratar temas censurados, e incluso crear saberes en el inconsciente que lleven a la expansión de la norma.

Para poder dar cuenta de la relación entre cuerpo, ética, estética y cine de autor, se emplerá la propuesta de Jean Luc Godard, director francés, surgido de la Nueva Ola Francesa ${ }^{1}$, impulsada por André Bazin y seguida por un grupo de críticos de cine que no encontraban en las expresiones artísticas de ese momento alguna que mostrara su posición política que pasaba por el coqueteo con lo ideológico, en sus diversas vertientes y con lo subjetivo al mismo tiempo.

\section{La técnica y estética en el cine posmoderno}

Históricamente la técnica ha significado, en el cine mercantilizado, un paquete sin contenido que atrapa a los espectadores en una fantasía, donde la imagen debe ser "lo más real posible" pero a la vez, donde las inverosimilitudes en que se ve envuelto el cuerpo, se convierten en el medio perfecto para demostrar un final total. Ejemplo de ello son los desenlaces de "salvación del mundo", el matrimonio de una pareja y el "fueron felices por siempre". La técnica es solo un medio que justifica la linealidad de la película. Tal como sabemos, el arte como algo ideologizado puede ser utilizado como una forma de educar al colectivo social sin que se den cuenta. Por lo tanto aún en las películas más "vacías" existen objetivos, argumentos que se desean demostrar y estrategias de disciplinamiento político. Es decir, se trata de mantener nuestra mirada en la pasividad y nuestro cuerpo en la inactividad.

la función del cine [hegemónico] consiste en reproducir, tan cuidadosamente como sea posible, las denominadas condiciones naturales de la percepción humana. Las técnicas (como la profundidad de campo) y los movimientos de la cámara (determinados por la acción del protagonista), combinados con la invisibilidad de montaje (exigida por el realismo), tienden a desdibujar los límites del espacio de la pantalla. El protagonista masculino es libre para gobernar la escena, una escena de ilusión espacial en la que es él quien articula la mirada y crea la acción (Mulvey, 1997, p. 372).

Ese juego es utilizado en el cine tradicional hollywoodense, en donde el hombre moderno es ubicado en el lugar de lo indestructible (lo omnipotente) y, aún así, la premisa de la filosofía racionalista moderna es probada a través de la imagen, flexibilizando la "realidad" con el uso de la técnica, pero sin dejar cabida al cuestionamiento, a pesar del uso exagerado e hiperbólico de la fantasía. El ser humano que se presenta allí es una representación fáctica del "promedio", aunque vuele, aunque lea el pensamiento, aunque logre salvar al mundo. Ese sujetohéroe, masculino es nuestro objeto de identificación (Mulvey, 1975).

A pesar de que en el cine hollywoodense se echa mano de lo hiperbólico, el concepto humanista y patriarcal de la sociedad sigue siendo incuestionable. Cuestión que se ve revertida en la propuesta de Godard en donde la técnica es utilizada para dar cabida al contenido y lo existencial. En este director, fundamentalmente en el primer periodo de su producción artística, se hace una parodia de la realidad a través de la técnica, no para alejarse de ella sino porque en la parodia, en el chiste, en la burla, se encuentra el centro mismo de la realidad actual, del performance que es la vida, pues no hay nada más real que la burla (Freud, 1905a). 
Lo "real" y "sexualmente fáctico" son construcciones fantasmáticas-ilusiones de sustancia a las que los cuerpos están obligados a acercarse aunque nunca puedan l... hay lo original lo auténtico y lo real también están constituidos como efectos (Butler, 1990, p. 284).

En Godard, podemos ver el uso del montaje ideológico² de una forma paródica y llevada al extremo. En películas como A bout de souffle (Al final de la escapada) se dan varias escenas en donde se decide eliminar todo el contenido innecesario, con el fin de aumentar la rapidez de las escenas y llevar a los espectadores hacia un punto, una idea clara. En una misma escena y en algunos minutos, el protagonista fuma un cigarro, se pone una camisa, habla con su pareja, todo esto a través de imágenes cortadas, donde no es posible observar todo el proceso de una forma "realista", con lo cual hace chiste sobre los límites del tiempo en la realidad y en el cine lineal. Sin embargo no por ello sus escenas dejan de mostrar realidades humanas, en este caso referidas a las relaciones conflictivas entre un hombre hegemónico y una mujer cisgénero con ciertos cuestionamientos sobre su vida y su forma de vincularse con el sujeto. La técnica, en escenas como la mencionada, hacen pensar que Godard corta con una tijera las realidades, las edita, se burla del cine y sus límites, se encuentra allí presente, para dar cabida "lo más pronto posible" al contenido subjetivo representado en la escena. Otras veces más bien deja correr el tiempo real, tan lentamente que nos sumergimos en un mundo casi de ensueño.

Se ha repetido hasta la saciedad que las nuevas estructuras cinematográficas propuestas por Godard eran el vehículo expresivo lógico para exponer una visión de mundo en crisis, desquiciado y absurdo, la técnica adecuada para plasmar la destrucción de las nociones de personaje, de psicología y de argumento. "un arte esquizofrénico para una época esquizofrénica" (Gubern, 1969, p. 20).

Justamente, desde la Modernidad Godard es leído como productor de un arte esquizoide. Cuando usa el montaje para cortar escenas, es considerado como un artista poco convencional, mientras que en otros momentos es criticado porque sus personajes miran la cámara (con lo cual es "demasiado real"). Ejemplo de ello es cuando en una discusión fundamental pasa un camión y debido al ruido que tapa el sonido de la conversación es imposible escuchar lo que los personajes dicen; o cuando dos personajes se encuentran de espaldas y no es posible ver sus caras, tan solo escuchar sus voces (un ejemplo claro de ello se ve en la escena de Vivre sa vie donde Nana habla con su expareja y solo podemos ver sus caras en algunos momentos, a través del espejo).

Todo esto, sin duda muestra una intencionalidad en Godard de usar la técnica para dar énfasis a ciertos aspectos que forman parte de la argumentación central. En el caso del uso del montaje y "pérdida de realismo", se puede pensar que desea dar énfasis a lo absurdo, hacer una burla de las convenciones temporales humanas; mientras que, por otra parte cuando vemos ese "realismo extremo", se trata, generalmente, de una intención explícita de ubicar a los sujetos observantes como parte de la película, en donde los espectadores o espectadoras no son sujetos omnipresentes, son también seres humanos.

A través de la técnica, se da una conexión con el tema central y con el contenido. La estética no es sólo un receptáculo vacío, sino que busca movilizar a los sujetos, hacerlos sentir parte y a la vez, cortar con convencionalismos innecesarios que solo alargan una "conversación" entre los personajes, el autor y ese tercero, que es el espectador. "El cinematógrafo se centra en el que percibe el tercer ojo, que mediatiza" (Winkler, 2005, p. 114). Es decir, siempre existe un tercero en ese arte voyeurista, que llena el deseo de ver y el deseo de ser otro, con fantasías tan cercana a las realidades cotidianas.

\section{Expresión de subjetividad como forma de activismo}

Tal como se anticipó en el apartado anterior, dedicado a la estética y el uso de la técnica como parte de la argumentación en el cine corporizado, la estética se convierte en ética cuando tiene razones políticas, como es el caso de las películas de Godard, fundamentalmente las rodadas en los $60 \mathrm{~s}$. La ética política está también presente en sus películas como transmisión de mensajes ideológicos (entendido como algo que pasa por el cuerpo y no sólo ideas panfletarias), es decir ese diálogo entre el autor, los personajes y el sujeto que mira se da de una forma poco dogmática, en donde se presenta a partir de la expresión de la subjetividad de los personajes, muchas veces contradictoria, visible a través de la exageración de los espacios (como en el caso de Alphaville, donde se lleva al extremo la perspectiva apocalíptica del mundo, pero con un tinte claro de realidad y actualidad).

Otro ejemplo de los mensajes ideológicos en las películas corporizadas de Godard es La Chinoise, en donde muestra una frase pintada en la pared "una minoría en la línea revolucionaria correcta no es más una minoría", frase que es tomada en diversas escenas, incluso cuando los personajes cuestionan la senda trazada de la revolución maoísta. Este es un filme en donde se puede ver que, a pesar de que Godard en ese momento se considera un militante de izquierda, no existe una postura panfletaria, como única forma de transmitir mensajes ideológicos. Incluso el empleo de lo cómico también juega un lugar fundamental con el que el autor pretende mostrar cómo una idea perseguida, puede ser también absurda cuando se lleva al extremo. Por ejemplo cuando, en la misma película, los jóvenes se despiertan con la Internacional Socialista y así empiezan sus actividades cotidianas. 
Al igual que se da una burla de los cuerpos, del tiempo y el espacio en ese cuerpo humano, a través de la técnica, también lo hace a través del contenido del mensaje. Existe un cuestionamiento constante del ideal de sujeto, al representarlo como vulnerable, susceptible a la duda, contradictorio, muchas veces estúpido y otras brillante. Un ejemplo de ese absurdo es el que vive el personaje principal masculino en la película Le mépris quien experimenta el desprecio de su pareja, sin que los espectadores podamos saber con certeza la razón. Esto nos moviliza a pensar posibles razones, a seguir a ese hombre en su penumbra y desesperación.

Le mépris es una metáfora de la manera en que la duda nos moviliza, un ejemplo de la desesperación que causa el sentirse vulnerable. Hace énfasis en la necesidad casi ontológica presente en los seres humanos de encontrar una razón de su tristeza. Pues cuando se está enamorada o enamorado se pierde de cierta manera el principio de realidad y de nuevo cuando ese supuesto amor sin límites es cuestionado el sujeto vuelve a ser cuerpo, llora, siente dolor. Ese sujeto (hombre hegemónico) deja de sentirse inmune a todo y pierde la certeza construida alrededor de ese otro. Nos damos cuenta de que aquello que nos gusta del amor, es la certeza de que nunca se va a acabar, el ideal de ser cuerpo completo.

De esta forma podemos observar cómo, en el cine de autor, ejemplificado en este caso por películas de Godard ya mencionadas, se desea dialogar con el sujeto que mira, llevándolo a cuestionar su propio cuerpo, su propio dolor y a transportarse de nuevo a los momentos en los que ha sentido desesperación. Se trata de una forma magistral de plantar una idea sin que esta tenga que ser explícita, sino movilizándonos desde nuestras propias experiencias. Aun en películas más político-ideológicas, como la antes mencionada La Chinoise, Godard invita a crear una perspectiva propia, que solo puede ser vivida si pasa por el cuerpo y por nuestras propias vulnerabilidades.

En este cuestionamiento político desprovisto de recetas, de ideas inamovibles, Godard demuestra la posibilidad de instaurar una idea, sin hacer uso del montaje soviético, donde tan solo se muestra una tesis y una antítesis (tal como se dijo, la síntesis es constituida por el sujeto que mira y se "vuelve" consciente). El cuestionamiento, la ambigüedad, el énfasis en la contradicción es la materia prima para el establecimiento de ideas contra-hegemónicas a través del cine.

El cine alternativo habilita un espacio en el que puede nacer un cine radical, tanto en sentido político como estético, que desafíe los supuestos básicos de la corriente cinematográfica dominante. No se trata de rechazar esta última desde un punto de vista moral, sino de destacar los modos en los que sus preocupaciones formales
reflejan las obsesiones psíquicas de la sociedad que lo ha producido y también de subrayar que el cine alternativo debe comenzar precisamente como reacción contra estas obsesiones y estos supuestos (Mulvey, 1973, p. 366).

La ética política, paralela a la estética congruente con esa crítica, puede ser presentada de diversas formas, no necesariamente haciendo énfasis en una emoción, una ideología o una posición como la única válida. Justamente, en este texto se desea hacer énfasis en que lo subjetivo y lo emocional, aquello que moviliza nuestro cuerpo también puede ser una forma radical de transformación política, individual y colectiva.

\section{3. ¿Materialidad versus subjetividad? Una dicotomía que se cuestiona en el cine corporizado}

La materialidad y la subjetividad, el cuerpo y el alma, el afuera y el adentro son dicotomías que desde la óptica moderna son excluyentes, a tal punto que se convierten en justificantes para el encarcelamiento de los sujetos (Foucault, 1975), "el alma es la cárcel del cuerpo" decía Foucault para explicar la forma en que la norma puede ser asumida por el sujeto mismo en una institución donde los cuerpos son moldeados casi por completo.

Debido a que el cine godardiano se presenta como ambiguo, causa angustia en los espectadores, una angustia que en algunos críticos ha sido razón para patologizar o subvalorar sus posiciones, sus técnicas e incluso su persona ${ }^{3}$. Esta crítica se da, principalmente, por parte de dos perspectivas, la de los intelectuales de izquierda que lo consideran un artista posmoderno, pues no presenta lo suficiente "la materialidad", las condiciones económicas de los personajes, las cuales sí se pueden observar en el montaje soviético o en el neorrealismo italiano. También recibe críticas por parte de los cineastas hegemónicos que le consideran un autor pretencioso y difícil de entender, en donde se critica la falta de linealidad en su argumento y sus guiones complejos y densos, es decir "demasiado ideologizados".

Todo esto dejando ver que Godard precisamente intenta unir ambos ámbitos del activismo artístico, lo material y lo subjetivo y por tanto, al no dar una respuesta lineal, un final feliz (tal como lo hace el cine hollywoodense), o debido a que no presenta un saber de izquierda dogmático y empaquetado (tal como lo hace el cine soviético), este autor es considerado como un artista incompleto y como sabemos, actualmente la incompletud es pensada como una carencia y no una virtud (Cabnal, 2010).

Es que, en Godard, los sonidos, los colores son actitudes del cuerpo, es decir, categorías: por tanto, encuentran su hilo en la composición estética que las atraviesa, en la organización social y política que las subtiende (Deleuze, 1987, p. 258-259)

Existe entonces una relación entre lo material y lo subjetivo como categorías no excluyentes, de manera tal que cuando hablamos del cuerpo en el cine de la nueva ola francesa y específicamente en Godard, podemos decir que en su 
expresión corporal también se encuentra su posición o posiciones políticas que están atravesadas por la subjetividad. El arte situado (Haraway, 1991) no sólo es un estilo, también es una posición transversal y micropolítica de la vida cotidiana, en el tanto hace temblar el estatus quo en un nivel sistémico, pero también en aquello innombrable y en el deseo mismo de las personas.

\section{4. Ética y estética como forma de rebelión}

La dicotomía difundida y legitimada por la hegemonía cultural de la modernidad es cuestionada constantemente por movimientos sociales, sujetos abyectos o subalternos y por el arte crítico, desde el teatro, la escritura, los performances y el cine, entre otras expresiones de pluralidad. De manera tal que, por ejemplo, en el cine de autor no se trata de poner por encima la forma o el fondo sino de combinar ambos elementos y jugar así con las certezas difundidas por el cine hollywoodense masivo.

André Bazin formuló hace casi veinte años una famosa distinción, ingeniosa y confortable, que dividía a los realizadores en dos categorías: Ios que creían en la imagen y los que creian en la realidad. Es decir los adeptos al cine-montaje y a respetaban tal realidad. La obra de Godard ha servido, al plano secuencia que retrar 1969, p. 23).

Justamente, esa división entre forma y fondo buscaba jerarquizar una o la otra. En la historia del cine moderno, occidental, lo estético generalmente era ubicado del lado de lo superficial, la fachada en donde se desarrollan los hechos, en donde se rueda la película, un ambiente desprovisto de cualquier simbolismo y cualquier relación con el argumento central. Por otra parte lo ético, es decir lo político iba del lado del dogma, con cineastas como Eisenstein o Vertov, quienes sientan las bases del montaje soviético como forma de transmitir una idea y crear la conciencia de clase.

El famoso Efecto Kuleshov ${ }^{4}$ desea mostrar que a través de la edición, es decir del montaje, es posible crear una u otra emoción en el público, sin que sea necesaria una expresividad exagerada en los personajes. Esta premisa básica es retomada por el cine soviético, que en plena Revolución Rusa utiliza el material cinematográfico como una forma de dogmatización. Este cine parte de la idea de que solo es necesario presentar al público una tesis y una antítesis, pues el sujeto, creará la síntesis gracias a su conciencia, tal como si se tratara de un individuo completamente racional. Se trata del uso ideológico del arte, en donde se presenta una estética cuyos símbolos son bastante densos, los actores no deben exagerar y las emociones no son orientadas hacia el sujeto sino hacia la instauración de un deseo colectivo.

A pesar de que el cine soviético buscaba la instauración de una idea en el "hombre racional" proletario, recibe muchas críticas debido a que parte de la premisa de una conciencia que antecede a la acción. Es necesario que las personas logren crear la síntesis en sus pensamientos, a través de las metáforas presentadas, para que se logre una verdadera revolución. Sin embargo, sucedía que esa síntesis era difícil de realizar y ese montaje intelectual quedaba sólo en una representación panfletaria de la izquierda, sin que en realidad este tipo de cine creara una reacción positiva hacia la revolución o al menos un expresión no dogmática de los ideales revolucionarios.

Es precisamente este tipo de montaje el que retoma Godard en muchas de sus obras, por lo cual ha sido ampliamente criticado pues tal como se dijo anteriormente, se considera un uso extremo de la edición, cortando el supuesto naturalismo del cine. El realismo se ve impreso más bien en el contenido subjetivo de su obra, es decir, en el uso del cuerpo como forma de probar la vulnerabilidad humana, que lleva a Godard a un materialismo que parte del sujeto y que, no por ello, deja de ser también ideológico. Sobre todo si entendemos que "el cuerpo no es un fenómeno estático, sino un modo de intencionalidad, una fuerza direccional y un modo de deseo" (Butler, 1998, p. 12). Existe en este autor una fusión entre la materia y el sujeto, la teoría y la práctica revolucionaria.

Conforme a lo mencionado ya en apartados anteriores y reiterado en este último punto, el cine de autor representa una salida a esa binarización de los cuerpos, a ese biopoder que traspasa nuestra existencia. Aun cuando este arte ha funcionado en las sociedades modernas como una forma de control social, tal como si se tratase de un panóptico invertido en donde el sujeto que mira es manipulado.

El arte puede funcionar como estrategia ética y estética de rebelión, de movilización de la norma, una norma que tal y como vimos, puede ser categórica, rígida y mercantilizada, como es el caso del cine, pero que con gran valentía puede ser cuestionada. Hacer cine de autor es una forma de mover esa norma, pero también lo es el cuestionamiento de nuestras propias sujeciones a través de la imagen en movimiento. La lucha colectiva no tiene por qué ser homogénea, tal como tampoco lo son nuestras interpretaciones de lo que vemos y hacemos.

\section{Conclusiones}

Este artículo coloca al cine de Jean-Luc Godard como representante simbólico de la entrada del sujeto en las representaciones estéticas, sin embargo es evidente que no se trata de la única expresión de la unión entre la imagen 
en movimiento y las movilización de emociones, a veces incomprensibles. Sin embargo, debido a las críticas que recibe y a su extensa obra, así como a la propuesta de diversas técnicas antes desconocidas en el cine se considera uno de los autores más importantes de nuestra época. La subjetivación, que podríamos llamar posestructuralista, del cine, lo vuelve algo profundamente político, en tanto da cabida a las corporalidades diversas, a la contradicción inconsciente, desde las emociones, desde aquello que nos moviliza en lo simbólico y en lo real, pero nunca, desde la imposición panfletaria del "deber sentir" o de las ideologías cerradas.

El cine de autor, posiciona al cuerpo y al ser humano como imperfecto, vulnerable y subjetivo. El cine de Godard, fundamentalmente desde finales de los 50 s y los años 60s, es cuerpo porque en su técnica, en el uso de la cámara, del espacio, de la fotografía, del montaje, es posible ver, sin que esté explícitamente presente, el cuerpo de Godard y a los "espectadores" nos da un lugar de acción, de interpretación. En el contenido de sus películas en los temas que trata en ellas presenta no sólo la existencia de personajes individuales, sino que fundamentalmente reivindica la alteridad. Ambas cuestiones, contenido y forma, se encuentran unidas en la técnica corporizada y el contenido subjetivado.

Se trata de una fusión que convierte al cine en cuerpo. Estudiar, en el cinecuerpo, la técnica como componente estético y lo ideológico como hecho éticopolítico lleva a pensar en el arte cinematográfico como una posibilidad revolucionaria y como una tecnología social (De Lauretis, 1990) susceptible de ser cuestionada, movilizada y decategorizada. El cine crea aquello que nombra, pero también a través de la imagen es posible reconocer cuerpos que anteriormente no eran reconocidos, puede tratar temas censurados, puede incluso crear saberes en el inconsciente que lleven a la expansión de las categorías, repensar nuestra existencia.

\section{Notas}

1. Surgido de la izquierda francesa, la nueva ola o el cine de autor, representa una forma subjetiva, de defender una ideología. A través del llamado montaje ideológico (para más información revisar la obra de André Bazin), el cine de autor toma ese tipo de montaje y lo lleva, ya no a la expresión dogmática de ideología, sino a una expresión política a través del sujeto, de su cuerpo, sus emociones; no se trata necesariamente de implantar una idea nueva sino de cuestionar las ideas existentes.

2. Esta categoría es conocida en el contexto audiovisual como una forma de edición en donde Ee asume la capacidad de los espectadores de lograr una sintesis a partir de la visualización se asume la capacidad de los espectadies de lograr una sintesíc a partir de la visualización Eisenstein, director de una de las olas más importantes del cine en la Unión Soviética y es fundamental en el tanto considera al sujeto como alguien activo que interpreta lo que ve. Sin embargo, como en el marxismo clásico, asume esta interpretación como racionalista, por lo tanto es también intelectualizada y excluyente de otro tipo de sensaciones.

3. No se trata aquí de dogmatizar el ideal de Godard como sujeto desposeído de falencias, tanto técnicas como ideológicas, pues precisamente lo que se trata de decir es que el cine de Godard, al ser un cuerpo, es incompleto, abierto, flexible, contextualizado y por tanto cuestionable. este texto, positemente responda a una estrategia utilizada por Godard ante la angustia de incompletud y ante la falta, presente en el cine de autor subjetivo.

4. Es el efecto emocional producido por el anclaje entre dos imágenes. Fue descubierto por Kuleshov, cuando este logró demostrar, que si se intercala la misma toma de un actor con las actor, aún cuando se trata de la misma fotografía. Es uno de los ejemplos más claros de que los espectadores no son entes pasivos sino que interpretan lo que se les presenta. Además es una prueba de cuán importante es el montaje en la producción cinematográfica.

\section{Referencias}

Bazin, A. (1990) ¿Qué es el cine?. Madrid: Ediciones Rialp.

Butler, J. (1990). El género en disputa. El feminismo y la subversión de la identidad. Barcelona: Paidós.

Butler, J. (1998). Sexo y género en El segundo sexo de Simone de Beauvoir. Revista Mora, (4), 10-21.

Butler, J. (2010). Marcos de guerra. Las vidas lloradas. Barcelona: Paidós.

Cabnal, L. (2010). Feminismos diversos: el feminismo comunitario. ACSUR. Recuperado de https://porunavidavivible.files.wordpress.com/2012/09/ feminismos-comunitario-lorena-cabnal.pdf

De Lauretis, T. (1992). Repensando el cine de mujeres. Teoría estética y feminista. 5, 251-277.

Deleuze, G. (1987). La imagen-tiempo: estudios sobre cine 2. Barcelona: Ediciones Paidós Ibérica.

Freud, S. (1905a). El chiste y su relación con lo inconsciente. Madrid: Amorrortu editores.

Freud, S. (1905b). Tres ensayos sobre la teoría sexual. Madrid: Ediciones Brontes. 
Foucault, M. [1975] (2008). Vigilar y castigar. Buenos Aires: Fondo de Cultura Económica.

Foucault, M. (1987). Hermenéutica del sujeto. Madrid: Ediciones de La Piqueta.

Gubern, R. (1969). Godard polémico. Barcelona: Tusquets editor.

Mulvey, L. (1973). Placer visual y cine narrativo. Valencia: Episteme ediciones.

Negri, A. (2009). El monstruo político. Vida desnuda y potencia. Buenos Aires: Paidós.

Spivak, G. (2003). ¿Puede hablar el sujeto subalterno?. Revista Colombiana de Antropología. 39, 297-364.

Winkler, P. (2005). La semiótica y el conocimiento científico: apuntes epistemológicos para la imagen en movimiento. Revista venezolana de información, 2 (3), 109-118.

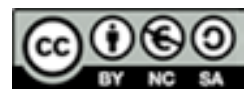

Esta obra está bajo una licencia de Creative Commons Reconocimiento

- NoComercial - CompartirIgual (by-nc-sa) 